Article

\title{
Spatial Distribution and Location Characteristics of Airbnb in Seoul, Korea
}

\author{
Donghwan Ki and Sugie Lee *(1) \\ Department of Urban Planning \& Engineering, Hanyang University, Seoul 04763, Korea \\ * Correspondence: sugielee@hanyang.ac.kr
}

Received: 8 June 2019; Accepted: 24 July 2019; Published: 30 July 2019

\begin{abstract}
The popularity of the sharing economy, including organizations such as Airbnb and Uber, has increased rapidly over the last few years. Regarding Airbnb, several studies have demonstrated potential problems related to it, such as rising housing costs and worsening residential environments. Despite its popularity and possibility of problems, however, the locational characteristics of Airbnb have not been thoroughly examined in the urban planning and public policy fields. Therefore, this study analyzed the locational characteristics of Airbnb in Seoul and identified potential problems in urban planning. First, we analyzed an operation status of Airbnb in terms of the commercial host. After that, we identified spatial distributions of Airbnb and examined influential factors that affected the locational characteristics of Airbnb using a negative binomial regression model. The results of this study are as follows. First, a considerable number of units were operated by commercial hosts, in contrast to the original concept of Airbnb as being part of the sharing economy. This finding indicates that there would be a potential conflict between Airbnb businesses and housing policy in urban areas. Second, Airbnb units were mainly located in residential areas, especially around multiplexes and townhouses. This finding indicates that Airbnb may decrease the availability of housing in the housing market. Third, Airbnb units were located preferentially in areas adjacent to universities or subway stations, as well as in areas with high ratios of single-person households. Considering these characteristics of Airbnb and the directions of government housing policy, urban scholars and policymakers should pay close attention to the potential conflict between the spatial distributions of Airbnb units and housing policies.
\end{abstract}

Keywords: sharing economy; Airbnb; spatial distribution; location characteristics; negative binomial regression

\section{Introduction}

The sharing economy is a co-consumption economy in which many people share products. Since the 2008 global financial crisis, this type of economy has emerged as an alternative that can help prevent contradictions and waste in modern capitalist society [1]. Under these circumstances, a variety of businesses have emerged, such as Airbnb and Uber. Airbnb, a leading sharing economy company, has proliferated since its establishment due to the advantages of renting unused space to guests and allowing users to experience local culture through their accommodations. Since launching in South Korea in 2013, the number of Airbnb units has increased by about 800\%, from 2000 in 2013 to 18,000 in August 2016 [2].

Negative effects of Airbnb have recently been mentioned in a few studies, including a lack of infrastructure, rising housing costs, waste, and noise [3,4]. Some issues are even leading to empirical research [5-10]. A few studies argued that the rapid growth of Airbnb encourages the possibility of excessive tourism or gentrification in specific areas [11-13]. The first sign of excessive tourism is a conflict between tourism stakeholders and residents because of excessive demand for limited 
resources, such as land, parking lots, and roads [11]. In particular, the number of Airbnb units may increase dramatically due to the low cost of scaling up and management compared to other lodging businesses, resulting in enhanced tourism pressure due to these characteristics of Airbnb $[13,14]$. In this situation, Gurran and Phibbs [7] insist that planners and policymakers need to cope with the surge in Airbnb units.

Thus, a better understanding of the spatial distribution of Airbnb units is needed to cope with the various urban problems that are related to Airbnb. Specifically, this study analyzed the operational status of Airbnb, focusing on commercial hosts to identify potential problems with Airbnb. Previous research also pointed out that the major cause of the problems with Airbnb is commercial hosts [6,15]. Afterward, this study analyzed the locational characteristics of Airbnb by considering the variables that are associated with Airbnb locations. These attempts could give useful insights to the following three questions: "Are there any potential problems caused by Airbnb?", "Where are Airbnbs located?", and "Which factors determine Airbnb locations?". The answers to these questions may help planners and policymakers cope with the surge of Airbnb in urban areas.

\section{Literature Review}

\subsection{Airbnb and Emerging Issues}

As the use of Airbnb has soared worldwide, several studies have identified its negative impacts. Specifically, Airbnb is associated with increases in housing rental costs, conflicts between residents and tourists, lack of parking lots, noise, and waste problems $[4,5,7,16]$. Studies on the deterioration of the residential environment caused by Airbnb have focused mainly on increases in housing costs [5-10]. Recently, Scott [5] analyzed the impact of Airbnb on housing prices in New York City and found that each 1 percent increase in the number of Airbnb units resulted in a 1.58 percent increase in housing prices. Gurran and Phibbs [7] also indicated that there is a considerable possibility for Airbnb to remove homes from the rental supply. This study mentioned that a conversion from housing to Airbnb takes place because the profit from Airbnb is higher than the profit from long-term renting. They also noted that this phenomenon is likely to be true not only in Sydney, where the study took place, but also in other cities. To deal with this problem, the authors argued that there was a need to modify zoning and control the residential developments.

Garcia-Ayllon [13] used several indicators such as the global tourist saturation index and P2P 2nd homes index of saturation that can measure the impact of Airbnb on neighborhoods. The results showed that there is a spatial correlation with tourist pressures, social conflict with tourism, and the alternation of rental estate markets. Therefore, this pattern generated other social imbalances and the phenomenon of tourist gentrification. Based on these studies, they reported that the negative impacts of Airbnb are geographically uneven [5,11-13]. Specifically, areas with negative impacts caused by Airbnb included heritage districts, traditional areas [13], or culturally desirable and internationally recognizable areas $[5,12]$.

There are two possible causes for these problems with Airbnb. First, Airbnb units are located in residential areas, since a fundamental attribute of Airbnb is the utilization of unused space $[6,11]$. In other words, Airbnb units are located in areas where there are few forms of tourist infrastructure, such as public transportation, parking lots, and waste disposal, which can cause damage to surrounding areas [3,4]. Second, Airbnb, which is based on the concept of a sharing economy, is now operating differently from its original intention. Although the original intention of Airbnb was to use unused space, some houses are currently used exclusively for Airbnb [4,6,7].

Commercial hosts who run two or more Airbnb units are arguably the most controversial issue regarding Airbnb problems [6,15]. As other cities have recently raised questions about sharing accommodations, bills to regulate sharing accommodations have been introduced. Specifically, laws have prohibited the renting of a house that is not occupied by the host or limited the length of the lease of such a house [11,17]. The regulatory targets could be the commercial hosts. Even a host with 
only one Airbnb unit may not reside in that house, but the limitations of the data do not distinguish where the host resides. However, a host who operates two or more units will certainly not be able to reside in at least one of the units. Thus, as in the research of Horn and Merante [6], a host that operates more than two Airbnb units was defined as a commercial host. Commercial hosts are subject to regulation because, if a host is not operating an Airbnb, the asset may be used as a house for lease and may not lead to a decrease in housing availability $[6,7]$.

\subsection{Locational Characteristics of Airbnb}

One of the most frequently asked questions for municipalities, hoteliers, and travelers is the locations of Airbnb units $[16,18]$. Thus, several studies have focused on the locational characteristics and distribution of Airbnb units. Gutiérrez et al. [11] compared the distribution and location characteristics of Airbnb units with those of hotels in Barcelona. Their study showed that Airbnb units are concentrated in the center of the city and are associated with the number of nearby leisure and restaurant facilities. The study also found that Airbnb units are located mainly in residential areas and that Airbnb may place tourism pressure on residential areas.

Quattrone et al. [16] analyzed the distribution of Airbnb units during 2012-2015 in London. They hypothesized that there would be a particular group that made a profit from Airbnb because Airbnb is a new accommodation peer to peer (P2P) platform. This study differs from our study by using demographic and socioeconomic variables to identify groups that make a profit through Airbnb. The analysis shows that the homeownership ratio variable has a negative relationship with the number of Airbnb units. This finding means that hosts lease, rather than own, houses to make a profit through Airbnb. In addition, the distance variable from the city center was shown to have a weak negative effect over time. This finding indicates that Airbnbs were initially located in the center of the city but have spread over time to surrounding areas. In a similar study, Zhang and Chen [18] analyzed Airbnb locations focusing on demographic characteristics.

Huh and Noh [4] analyzed the spatial distribution of Airbnb units in Seoul. This study compared the distribution of hotels and Airbnb units through nearest neighbor hierarchical clustering, an index of spatial dissimilarity that makes it possible to compare the spatial distribution. According to the results, Airbnb units in Seoul are concentrated in the downtown, Hongdae, and Gangnam areas, which are typical tourist spots. Compared to the location of hotels, Airbnb units appear to be more widespread. This result is because hotels in Seoul can only be located in commercial areas, but Airbnb units can be located in all land use areas. This study also mentioned possible conflicts between residents and Airbnb users, as 70 percent of Airbnb units in Seoul are located in residential areas.

Thus, several studies analyzed the locational characteristics of Airbnb. Some of them focused on demographic variables to identify the groups that benefited from Airbnb [16,18]. Some studies only analyzed the distribution status of Airbnb, not the locational characteristics [4]. Also, their $[16,18]$ approach is not suitable in our study area. A considerable number of hosts in Seoul are commercial hosts (see Table 3), which indicates that a socioeconomic characteristic of the area is not representative of a host's features. Therefore, this study is noteworthy in that it analyzed the location characteristics of Airbnb focusing on the built environment characteristics such as housing, land use, and transportation infrastructure.

Airbnb and hotels have common characteristics as a lodging business. However, there is little research on the locational characteristics of Airbnb compared to hotels. Research on the locational characteristics of hotels was conducted mainly using aspects of the performance of the room as dependent variables such as occupancy rate, average daily rate, and revenue per available room. Locational factors that impact hotel performance are primarily divided into the distance to destinations (e.g., airports, CBD, tourist attractions), the distance to public transportation (e.g., subways, bus stations), population and economic indicators (e.g., population density, median income, GDP), and other issues (e.g., safety, agglomeration) [19-21]. 
However, hotels and Airbnb units are likely to have some differences in locational characteristics due to their different users. Since Airbnb focuses on longer-term leisure travelers instead of the short-stay business travelers integral to many hotels [21], Airbnb users are more tourist-oriented than those of hotels. The locational differences between hotels and Airbnb units are as follows. Song et al. [22] mentioned that, due to the characteristics of hotel users (business-oriented), alternative forms of transportation such as shuttle buses or cars are more likely to be used than public transportation. However, in the case of Airbnb, public transportation is relatively important because users mainly consisted of foreign travelers, who may not have a transportation alternative. In fact, according to a survey of foreigner tourists conducted in Seoul, about 90 percent of them use public transportation as their main mode of transportation [23]. This means that aspects of public transportation infrastructure, such as mobility and accessibility, are very important for the location of Airbnb units. Nevertheless, previous studies on the locations of hotels, and even Airbnb, have quantified public transportation infrastructure only roughly, that is, using a linear distance to tourist attractions, airport, or the city center. Linear distance is different from travel distance, and it is unable to reflect public transportation mobility. There is a possibility that, if local public transportation is good, it can take a short time to reach tourist attractions even though the distance is relatively far.

\section{Methodology}

\subsection{Study Area and the Unit of Analysis}

This study focused on Seoul, the capital city of South Korea (Figure 1). The area of Seoul is 605 square kilometers, the population is 9.7 million, and it is a densely populated city. As of 2016, the number of overnight international visitors to Seoul ranked seventh highest in the world, at 12.39 million [24].

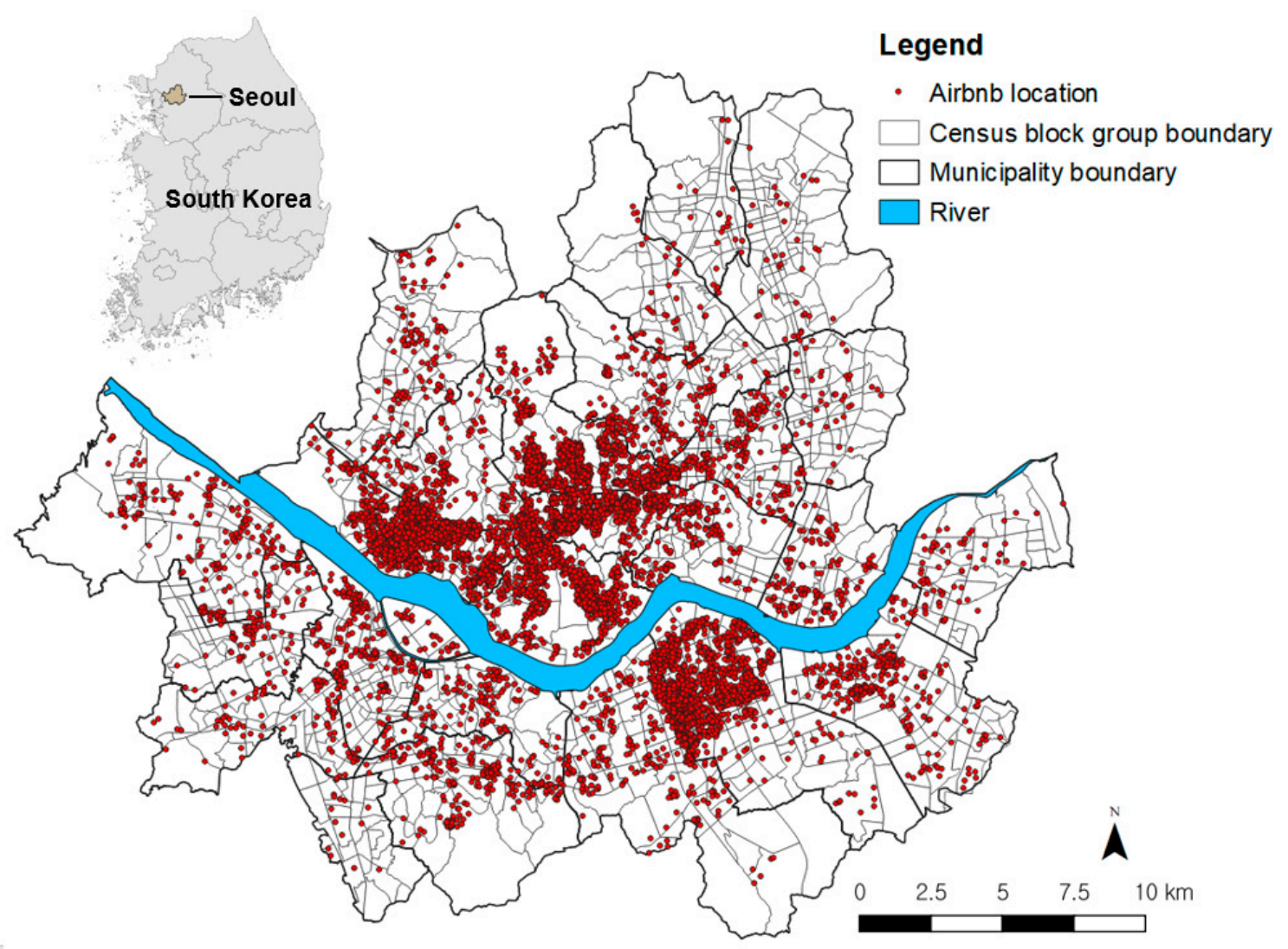

Figure 1. Locations of Airbnb and units of analysis in the city of Seoul. 
Considering that 78.8 percent of foreign tourists who visited South Korea visited Seoul [25] and that the number of Airbnb units in South Korea has increased by 800 percent over the past three years [2], it is estimated that the number of Airbnb units in Seoul has also increased sharply. Under these circumstances, Seoul also has reported various problems such as noise, litter, and security concerns due to Airbnb [2,4]. Also, the time scope of the study is 17 July 2017, which is the latest available data. The unit of analysis used in this study is the census block group ('Dae-guyeog' in Korean), which is a statistical area separated by clear landmarks such as roads, waterways, and ridges [26] (Figure 1). There are 1420 census block groups in Seoul, and the average area is 0.42 square kilometers. However, four census block groups are composed entirely of green areas. Therefore, 1416 census block groups were utilized.

\subsection{Variable Selection}

Table 1 shows the variables and their descriptions. The dependent variable is the total number of Airbnb units in each unit of analysis in Seoul. This study used Airbnb geo-located data for 12 temporal points from May 29, 2016, to July 17, 2017. The original data is from the Tom-slee website (tomslee.net). He scraped the Airbnb website and uploaded data on Airbnb locations in several cities. This data contains Airbnb units ID, host ID, number of reviews, and location information (longitude and latitude).

Table 1. Description of variables.

\begin{tabular}{|c|c|c|c|}
\hline Variable & & Definition & Unit \\
\hline No. of Airbnb units & & & no. \\
\hline \multirow{4}{*}{ Housing } & Size & $\begin{array}{l}\text { Ratio of small housing } \\
\text { Ratio of medium housing } \\
\text { Ratio of large housing }\end{array}$ & \multirow{2}{*}{ ratio } \\
\hline & Type & $\begin{array}{l}\text { Ratio of multiplex \& townhouse } \\
\text { Ratio of single-family housing } \\
\text { Ratio of apartment } \\
\text { Ratio of other housing }\end{array}$ & \\
\hline & Unit & No. of housing unit & no. \\
\hline & Price & $\begin{array}{l}\text { Medium housing price } \\
\text { Medium housing price }{ }^{2}\end{array}$ & $\$ 1000 / \mathrm{m}^{2}$ \\
\hline Land use & & $\begin{array}{l}\text { Urbanized area } \\
\text { Land use mix (RNR) }\end{array}$ & $\mathrm{km}^{2}$ \\
\hline Population & & Ratio of single-person household & ratio \\
\hline \multirow{2}{*}{ Public transportation } & Mobility & $\begin{array}{l}\text { Travel time to airport } \\
\text { Travel time to tourist spot }\end{array}$ & $\min$. \\
\hline & Accessibility & $\begin{array}{l}\text { Distance to bus stop } \\
\text { Distance to subway station } \\
\text { Distance to subway station }^{2}\end{array}$ & $\begin{array}{l}\mathrm{m} \\
\mathrm{km}\end{array}$ \\
\hline Lodging & & No. of other lodging & no. \\
\hline Amenities & & $\begin{array}{l}\text { No. of convenience stores } \\
\text { Distance to police station } \\
\text { Distance to university }\end{array}$ & $\begin{array}{l}\text { no. } \\
\text { m }\end{array}$ \\
\hline
\end{tabular}

This study considered independent variables that are expected to be related to the location of Airbnb and classified them as housing, land use, population characteristics, public transportation, lodging, and amenities. The fundamental attribute of each Airbnb unit is transferred from the original housing, so they may be related to the housing properties of the area where the Airbnb unit is located. Therefore, housing variables were subdivided into housing size and type, a number of housing units, and housing prices. For housing price variables, the squared variable was added because it was 
expected that there would be an appropriate housing price in the area where Airbnb units are located. This is because some hosts can rent out and operate Airbnb without owning a house [16].

For land use, urbanized area and land use mix variables were used. There may be a difference in the number of Airbnb units because the urbanized area varies with the analysis unit. In other words, in the case of census block groups with large urbanized areas, there may be more Airbnb units than in other census block groups, even within the same location characteristics. This problem was controlled by adding the urbanized area as an exposure variable. Land use mix, quantified using the residential and non-residential index (RNR), was used because a reasonable mix of land use, such as commercial facility or a leisure facility might act as an amenity.

In recent years, the government's housing policy has been focused on the single-person household, because of its proliferation. Therefore, we add the ratio of single person household variable to examine the relationship between them. Although this research focused on the built environment, this study included socioeconomic variables such as housing price and single-person household. These variables are important factors to explain a potential conflict between Airbnb units and housing in residential areas.

The public transport infrastructure variables consisted of mobility and accessibility. Given that the main users of Airbnb are foreign tourists, public transportation is one of the most important factors for Airbnb users. As mentioned above, it is necessary to establish more detailed public transport infrastructure variables. Google Direction API has the advantage that it can determine the public transportation travel time between origin and destination considering traffic conditions, vehicle interval, and travel distance $[27,28]$. To produce more accurate mobility, travel time calculation using Google Direction API should be performed at the same time as the analysis data (17 July 2017). However, this study calculated mobility measures as of 29 June 2018, at 12 p.m. because the Google Direction API service does not calculate past transportation mobility.

Considering that the primary users of Airbnb are foreign tourists, mobility to Incheon International Airport, a representative airport near Seoul, was calculated first. Second, to calculate the mobility to tourist spots, this study referred to the International Tourists Survey conducted by the Korean Tourism Organization in 2017 [25]. We extracted ten major tourist attractions (Table 2) visited by foreigners and calculated the travel time to each spot. Then, we calculated the travel time to tourist spots by weighting the ratio of the visit percentage to each tourist spot.

Table 2. Major tourist spots visited by foreign tourists.

\begin{tabular}{lc}
\hline Tourist Spots & Visit Percentage (\%) \\
\hline Myeong-dong & 22.46 \\
Dongdaemun History \& Culture Park & 16.29 \\
Gyeongbok Palace & 11.17 \\
Namsan Tower & 10.50 \\
Hoehyeon & 8.98 \\
Hongdae & 8.95 \\
Gangnam & 8.11 \\
Anguk & 7.09 \\
Itaewon & 6.43 \\
\hline Total & 100 \\
\hline
\end{tabular}

For accessibility, the distance from the center point of the census block group to the nearest transportation stop was calculated. For Airbnb users, who use mainly public transportation, the distance to a public transport stop is expected to be considered, which may affect the location of Airbnb units. Public transportation stops were classified as bus and subway stations. For the distance to a subway station, the squared variable was added because there would be a distance threshold from the subway station. In other words, we expected that the relationship between Airbnb units and distance to a 
subway station is not linear. If the distance is too far from a subway station, the benefits of accessibility to the subway system may disappear.

The other lodging variable, such as hotels and motels, is a reflection of tourist spots, and it can be compared with the locations of Airbnb units. For amenities variables, this study considered the number of convenience stores, distance to the nearest police station, and distance to the nearest university. As a representative retail business, 9777 convenience stores were located in Seoul. The proximity to a retail store could be considered when deciding the location of accommodations for tourists. This study used distance to a police station as a proxy for safety. Around a university, there are many possible amenities relevant to Airbnb users, such as bars, restaurants, leisure facilities, and entertainment facilities. Also, there are many single-person housing units used by university students. Therefore, this study uses the variable to identify the relationship between Airbnb and the location of housing for young people.

\subsection{Methods}

This study aims to examine the potential problems and location characteristics of Airbnb. To achieve the goal, the analysis was conducted in two stages. First, the operation status of Airbnb was analyzed to assess the possibility of problems of Airbnb. As legislation and research on Airbnb indicate that commercial hosts were the cause of Airbnb's problems, the study analyzed the operational status of Airbnb with a focus on commercial hosts. In addition, through the analysis of Airbnb distribution, the spatial distribution of problems that could be caused by Airbnb was determined and used as basic data for location characteristics. Afterward, the change between two points of time was determined using the data from 29 May 2016, and 17 July 2017, which are the earliest and latest dates from the Airbnb dataset, to identify the degree of change and spread of potential problems. Second, this study constructed variables that were expected to affect the location of Airbnb units, and statistically significant variables were determined through negative binomial regression analysis.

The dependent variable of this study is count data, which is the number of Airbnb units in each unit of analysis. If the dependent variable is count data, Poisson regression or negative binomial regression are generally used [29]. Poisson regression has the constraint that variance is equal to the mean, and it can be determined from the variance to mean ratio (VMR). The VMR was 88.37 , indicating that a negative binomial regression is appropriate.

Besides, the number of zero values in this study is $425(30 \%)$, which shows a zero-inflated distribution. If the percentage of zero values is greater than $30 \%$, it might be appropriate to use a zero-inflated model [30]. However, as the author mentioned, this is not an objective figure, so the analysis method can be determined effectively by comparing the model fit. Therefore, in this study, because the samples with a zero value comprise $30 \%$ of the whole sample, we conducted a Vuong test to verify the suitability of negative binomial regression and zero-inflated negative binomial regression. As a result of the Vuong test, the $p$-value was 0.320 , which means that the negative binomial regression is more suitable than the zero-inflated negative binomial regression.

Figure 1 shows that Airbnb units are concentrated in specific areas. This finding indicates that Airbnb units are predicted to be spatially correlated with other units observed nearby. Therefore, we calculated Moran's I value. A Moran's I value of $0.516(p=0.000)$ indicated that the degree of spatial auto-correlation was significant. This result means there is a need to control the spatial auto-correlation. Some methods have been used to mitigate spatial autocorrelation in previous studies when using negative binomial regression. A method to reduce spatial autocorrelation is adding an auto-covariate as an independent variable in the model [31-34], and it can be applicable to both binomial and Poisson distributions [32]. The auto-covariate is a method that controls spatial autocorrelation by measuring the effect of a dependent variable at one point on a dependent variable at another point, as shown in Equation (1) [34]. Therefore, this study used negative binomial regression with the auto-covariate as the final statistical model.

$$
A_{i}=\sum_{j \in k_{i}} w_{i j} y_{j}
$$


where

$A_{i}$ is the authocovariate

$y_{j}$ is the dependent variable (site $j$ )

$k_{i}$ is the $i^{\prime}$ s neighbors

$w_{i j}$ is the weight given to the influence of site $j$ over site $i$

\section{Results}

\subsection{Status of Airbnb}

Table 3 shows the operation status of Airbnb in Seoul. Airbnb units increased from 8519 in 2016 to 12,406 in 2017, an increase of 3887 units (45.6\%). The number of Airbnb units per host increased slightly, from 2.37 to 2.45 . In 2017, commercial hosts accounted for $39.2 \%$ of all hosts. Additionally, commercial hosts owned $75.2 \%$ of Airbnb units. Super-commercial hosts are hosts who own more than 10 Airbnb units, accounting for only $3.6 \%$ of hosts but $22 \%$ of the total Airbnb units.

Table 3. Operation status of Airbnb units for global cities.

\begin{tabular}{lllllllll}
\hline \multirow{2}{*}{ Category } & May 2016 & \multicolumn{7}{c}{ July 2017 } \\
\cline { 2 - 9 } & Seoul & Seoul & Sydney & Boston & New York & Porto & Lisbon & San Francisco \\
\hline Airbnb units (no.) & 8519 & 12,406 & 25,506 & 4705 & 41,245 & 5664 & 13,578 & 8344 \\
\hline Hosts (no.) & 3595 & 5066 & 20,088 & 2686 & 34,688 & 2771 & 6457 & 6777 \\
\hline Airbnb units per host (-) & 2.37 & 2.45 & 1.27 & 1.75 & 1.19 & 2.07 & 2.10 & 1.23 \\
\hline $\begin{array}{l}\text { Maximum Airbnb units per } \\
\text { host (no.) }\end{array}$ & 45 & 67 & 169 & 149 & 28 & 45 & 185 & 69 \\
\hline $\begin{array}{l}\text { Percentage of commercial } \\
\text { hosts (\%) }\end{array}$ & 38.80 & 39.16 & 12.18 & 20.85 & 11.77 & 35.27 & 30.53 & 12.73 \\
\hline $\begin{array}{l}\text { Percentage of units owned } \\
\text { by a commercial host (\%) }\end{array}$ & 74.18 & 75.16 & 30.84 & 54.81 & 25.80 & 68.68 & 66.96 & 29.12 \\
\hline $\begin{array}{l}\text { Percentage of } \\
\text { super-commercial hosts (\%) }\end{array}$ & 3.23 & 3.61 & 0.35 & 1.38 & 0.08 & 1.86 & 2.49 & 0.24 \\
\hline $\begin{array}{l}\text { Percentage of units owned } \\
\text { by a super-commercial } \\
\text { host (\%) }\end{array}$ & 19.29 & 21.99 & 7.30 & 22.40 & 0.85 & 14.92 & 23.75 & 3.72 \\
\hline
\end{tabular}

To compare the potential problems caused by Airbnb in Seoul, this study selected Sydney, Boston, New York, Porto, Lisbon, and San Francisco as comparable cities. These cities were selected because existing studies on these cities indicated emerging urban problems caused by Airbnb $[5-7,9,10]$. As shown in Table 3, the city of Seoul showed higher values than other cities in terms of the average number of units per host, the percentage of commercial hosts, and the percentage of Airbnb units owned by commercial hosts.

To summarize, a larger number of Airbnb units in Seoul were operating for commercial purposes than in overseas cities. Although only one year of data was considered, this pattern can be seen as an increasing trend. This finding means that there is a possibility that problems associated with Airbnb could also arise in Seoul. In addition, given the extent of commercial operation status, the problems are likely to be more serious than for other cities.

Figure 2 shows that the number of Airbnb units in a census block group and major tourist attractions in Seoul. We can identify that a large amount of Airbnb units were distributed around the major tourist attractions. The characteristics of these spots are as follows. Hongdae has excellent public transportation mobility to Incheon International Airport because of the airport railroad. In addition, Hongdae has a variety of amenities, such as fashion retail and entertainment venues. Myeong-dong and Seoul station are located near the center of the downtown area and have various amenities. In particular, Seoul station has good accessibility to airport because a link for the airport railway is located there. Bukchon and Insa-dong are crowded with traditional Korean houses, which indicates that tourists can 
have the experience of "living like a local," which is one of the reasons for the success of Airbnb [11]. Itaewon and Gangnam also are popular tourist spots in Seoul. These tourist spots have common features of good transportation infrastructure or various amenities such as shops or entertainment.

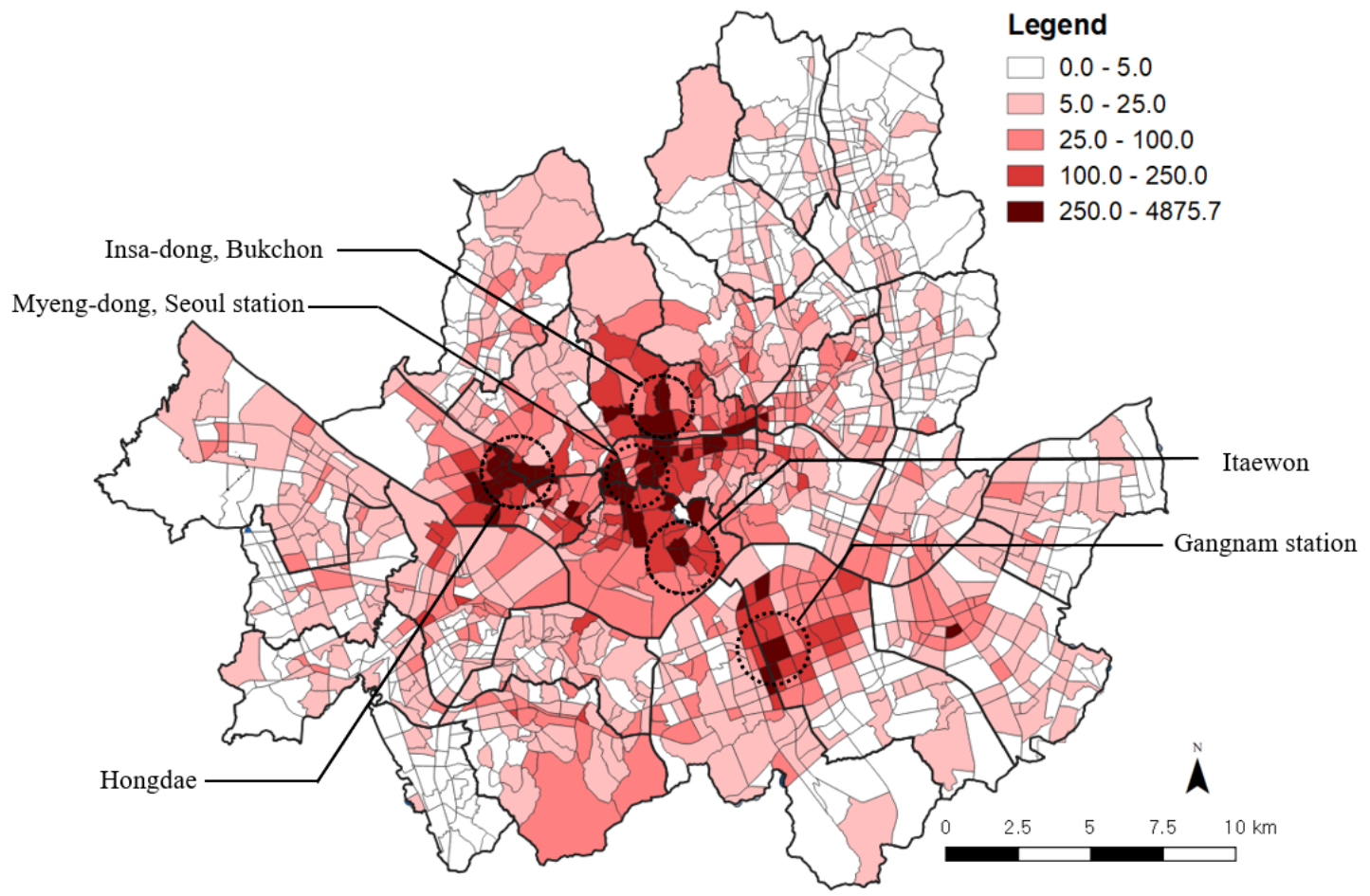

Figure 2. Airbnb density by the unit of analysis in Seoul (2017).

To identify the degree of spatial diffusion of Airbnb in one year, this study compared the location data for May 2016 and July 2017 (Figure 3). Airbnb units increased in 645 (45.55\%) of the total analysis units, while they decreased in 225 of the analysis units (15.89\%). If we look at the areas where a change in the number of units occurred, it is clear that the growth of Airbnb units was concentrated in Myeong-dong, Hongdae, and around Gangnam Station, which are major tourist spots. Additionally, the analysis units with increased numbers of Airbnb units are spread throughout Seoul. Quattrone et al. [16] reported that Airbnb units are initially focused in tourist spots and the center of a city, but as time passes, Airbnb units spread to the peripheral residential areas.

\subsection{Descriptive Analysis}

Before the descriptive analysis, this study calculated the variance inflation factor (VIF) and then detected multicollinearity in the housing size and type variables (VIF $>10$ ). Therefore, we eliminated the ratio of medium-size housing and apartment variables, which were not the focus variables in our study.

Table 4 is the result of the descriptive analysis. The average number of Airbnb units in a census block group is 8.76 , with a minimum of 0 and maximum of 548 . On average, the ratio of single-person households stands at 31\%. Due to the surging numbers of single-person households, various issues such as housing shortages have become an issue [35]. The median housing price is 5.34 thousand dollars per square meter, with a significant range between minimum and maximum prices of 2.33 and 19.75 thousand dollars per square meter. In terms of public transportation accessibility, the distances to subway entrances and bus stops are $512 \mathrm{~m}$ and $161 \mathrm{~m}$, respectively, which means that public transportation accessibility is quite good in Seoul. 


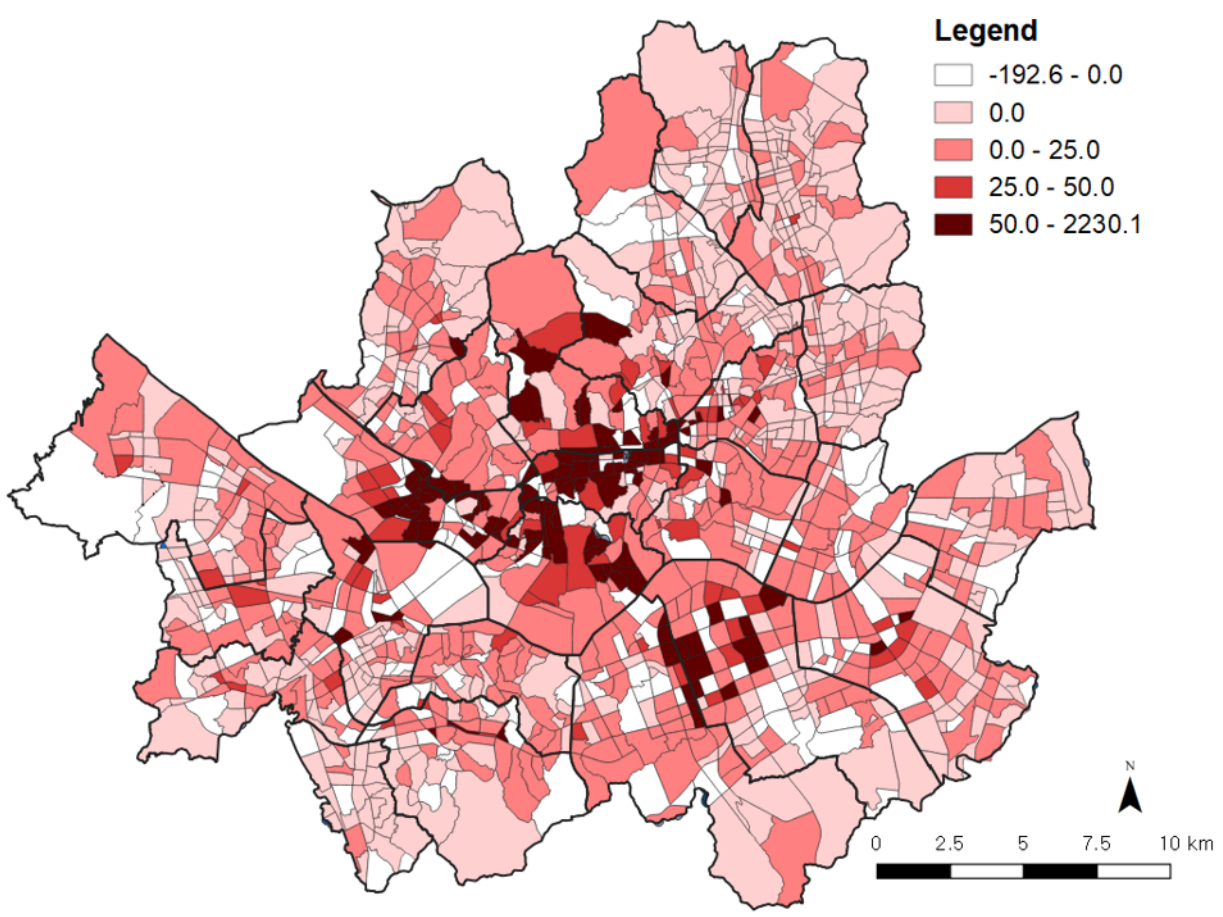

Figure 3. Changes in the density of Airbnb units by the unit of analysis in Seoul (2016-2017).

Table 4. Descriptive analysis.

\begin{tabular}{|c|c|c|c|c|c|c|}
\hline \multicolumn{2}{|l|}{ Variable } & Mean & Std. dev. & Min & $\operatorname{Max}$ & VIF \\
\hline \multicolumn{2}{|c|}{ No. of Airbnb units } & 8.76 & 27.82 & 0.00 & 548.00 & - \\
\hline \multirow{8}{*}{ Housing } & Ratio of small housing & 0.43 & 0.23 & 0.00 & 1.00 & 1.00 \\
\hline & Ratio of large housing & 0.25 & 0.21 & 0.00 & 1.00 & 1.00 \\
\hline & $\begin{array}{l}\text { Ratio of multiplex \& } \\
\text { townhouse }\end{array}$ & 0.26 & 0.25 & 0.00 & 1.00 & 1.63 \\
\hline & Ratio of single-family housing & 0.17 & 0.20 & 0.00 & 1.00 & 1.91 \\
\hline & Ratio of other housing & 0.09 & 0.18 & 0.00 & 1.00 & 2.58 \\
\hline & No. of housing & 1961.5 & 1574.2 & 0.00 & $11,129.5$ & 1.77 \\
\hline & Medium housing price & 5.34 & 2.30 & 2.33 & 19.75 & 19.47 \\
\hline & Medium housing price ${ }^{2}$ & 33.83 & 37.12 & 5.41 & 389.95 & 16.76 \\
\hline \multirow{2}{*}{ Land use } & Urbanized area & 0.22 & 0.23 & 0.01 & 5.92 & 1.60 \\
\hline & Land use mix (RNR) & 0.39 & 0.28 & 0.00 & 1.00 & 1.14 \\
\hline Population & $\begin{array}{l}\text { Ratio of single-person } \\
\text { household }\end{array}$ & 0.31 & 0.17 & 0.00 & 0.90 & 3.69 \\
\hline \multirow{5}{*}{$\begin{array}{l}\text { Public } \\
\text { transportation }\end{array}$} & Travel time to airport & 96.44 & 18.7 & 50.97 & 143.95 & 1.25 \\
\hline & Travel time to tourist spot & 40.44 & 10.34 & 13.24 & 70.52 & 2.15 \\
\hline & Distance to bus stop & 160.65 & 86.60 & 1.50 & 1270.40 & 1.33 \\
\hline & Distance to subway station & 512.30 & 410.19 & 15.80 & 3231.11 & 8.44 \\
\hline & Distance to subway station $^{2}$ & 430.61 & $873,930.00$ & 0.25 & $10,439.43$ & 7.69 \\
\hline Lodging & No. of other lodging & 2.64 & 6.38 & 0.00 & 77.00 & 1.24 \\
\hline \multirow{3}{*}{ Amenities } & No. of convenience stores & 6.89 & 6.77 & 0.00 & 55.00 & 1.73 \\
\hline & Distance to police station & 576.56 & 316.85 & 22.27 & 2631.48 & 1.30 \\
\hline & Distance to university & 1749.11 & 1230.75 & 34.27 & 7101.51 & 1.42 \\
\hline \multicolumn{2}{|l|}{ Auto-covariate } & 8.76 & 20.37 & 0.00 & 240.50 & 1.35 \\
\hline
\end{tabular}




\subsection{Locational Characteristics of Airbnb}

Table 5 shows the results of the negative binomial regression model. The housing size variables are not significant, but the housing type has a relationship with Airbnb units. The townhouse and single family house were found to have a negative and positive relationship, respectively. This is because the areas near Hongdae and Myeong-dong, where most Airbnb units are located, are mainly composed of townhouses, which reflects housing characteristics of these local areas. Single-family housing is usually located further from the city center and tourist sites than other types of housing. Also, due to the zoning system, amenities such as shops, stores, and entertainment, which are Airbnb's amenities, are difficult to establish near single-family housing areas. Since Airbnb units have the locational characteristics of operating near the city center, tourist spots, and other various convenient facilities such as shops or stores, the ratio of single-family housing is inversely correlated with the number of Airbnb units. However, the total number of housing units shows that Airbnb units are primarily located in residential areas. This finding explains the fundamental characteristic of Airbnb that is located in residential area. This characteristic is one of the reasons that Airbnb is causing problems by infiltrating residential areas that have the insufficient infrastructure for tourists, as mentioned above. Similarly, research on the distribution of Airbnb in Seoul showed that $70 \%$ of Airbnb units are located in residential areas [4].

Table 5. Negative binomial regression model for the number of Airbnb.

\begin{tabular}{|c|c|c|c|c|c|}
\hline Variable & & Coef. & Sig. & Std. Error & $\mathbf{z}$ \\
\hline \multirow{8}{*}{ Housing } & Ratio of small housing & -0.185 & & 0.203 & -0.91 \\
\hline & Ratio of large housing & 0.337 & & 0.204 & 1.55 \\
\hline & Ratio of multiplex \& townhouse & 0.749 & $* * *$ & 0.167 & 4.49 \\
\hline & Ratio of single-family housing & -0.437 & * & 0.225 & -1.95 \\
\hline & Ratio of other housing & -0.101 & & 0.285 & -0.36 \\
\hline & No. of housing & $1.457 \times 10^{-4}$ & $* * *$ & 0.000 & 4.89 \\
\hline & Medium housing price & 0.487 & $* * *$ & 0.063 & 7.71 \\
\hline & Medium housing price ${ }^{2}$ & -0.024 & $* * *$ & 0.004 & -6.38 \\
\hline \multirow{2}{*}{ Land use } & Urbanized area & 1.518 & $* * *$ & 0.272 & 5.57 \\
\hline & Land use mix (RNR) & 0.314 & $* *$ & 0.119 & 2.63 \\
\hline Population & Ratio of single-person household & 1.131 & $* * *$ & 0.345 & 3.80 \\
\hline \multirow{5}{*}{$\begin{array}{l}\text { Public } \\
\text { transportation }\end{array}$} & Travel time to airport & -0.012 & $* * *$ & 0.002 & -6.59 \\
\hline & Travel time to tourist spot & -0.047 & $* * *$ & 0.004 & -10.75 \\
\hline & Distance to bus stop & $-1.900 \times 10^{-5}$ & & 0.000 & -0.05 \\
\hline & Distance to subway station & $-6.013 \times 10^{-4}$ & * & 0.000 & -2.50 \\
\hline & Distance to subway station ${ }^{2}$ & $3.540 \times 10^{-7}$ & $* * *$ & 0.000 & 3.27 \\
\hline Lodging & No. of other lodging & 0.020 & $* * *$ & 0.005 & 3.63 \\
\hline \multirow{3}{*}{ Amenities } & No. of convenience stores & 0.025 & $* * *$ & 0.007 & 3.66 \\
\hline & Distance to police station & $5.130 \times 10^{-5}$ & & 0.000 & 0.48 \\
\hline & Distance to university & $5.580 \times 10^{-5}$ & * & 0.000 & -2.07 \\
\hline \multicolumn{2}{|l|}{ Auto-covariate } & 0.287 & $* * *$ & 0.002 & 13.11 \\
\hline \multicolumn{2}{|l|}{ Cons. } & 0.820 & * & 0.337 & 2.43 \\
\hline \multicolumn{2}{|l|}{ No. of obs } & 1416 & & & \\
\hline \multicolumn{2}{|c|}{ Pseudo R2 } & 0.182 & & & \\
\hline \multicolumn{2}{|c|}{ Moran's I ( $p$-value) before auto-covariate } & $0.347(0.000)$ & & & \\
\hline \multicolumn{2}{|c|}{ Moran's I ( $p$-value) after auto-covariate } & $0.212(0.000)$ & & & \\
\hline
\end{tabular}

Note: ${ }^{*} p<0.05 ;{ }^{* *} p<0.01 ;{ }^{* * *} p<0.001$. 
The number of Airbnb units has increased with higher housing prices because various amenities are reflected in the value of regional housing prices. In other words, a higher housing price is the result of comfort, convenience, safety, and amenity, which could not be quantified in this study. However, the squared variable shows that Airbnb units have decreased from a peak price of 10,145 dollars per 1 square meter. This finding indicates that if the housing price exceeds a certain threshold, the rent for housing used by Airbnb is higher than the benefits of the amenities. Thus, the cost is greater than the benefit. However, considering the fact that the housing price can be raised by Airbnb, the relationship between housing price and Airbnb units may be not causality, but association.

In terms of land use, the urbanized area in the unit of analysis, which is an exposure variable, has a strong relationship with the number of Airbnb units. Also, the land use mix variable is statistically significant. Although Airbnb units are typically located in residential areas, other land uses such as commercial or leisure facilities may act as amenities. The ratio of single-person households, which is a population characteristic, is related to the number of Airbnb units. In addition, considering the conversion from the ordinary housing to Airbnb, a close examination of the impact of Airbnb on the housing market should be done in these areas.

Travel times to the Incheon International Airport and tourist spots calculated using Google Direction API are all significant, which indicates that public transportation mobility is a major factor in the location of Airbnb units. Because most foreign tourists use public transportation, excellent transportation mobility is essential to foreign tourists and the location of Airbnb units.

The accessibility to bus stops variable was not statistically significant, with only $7.7 \%$ of foreign tourists, the main users of Airbnb, using the bus as the main mode of transportation [23]. On the other hand, the distance to a subway entrance variable is significant. Further from a subway station, fewer Airbnb units were present, up to a certain distance. This is because $58.1 \%$ of foreign tourists use the subway as their main mode of transportation [23], and proximity to a subway station is a crucial factor for the location of Airbnb units, up to a threshold distance (Figure 4).

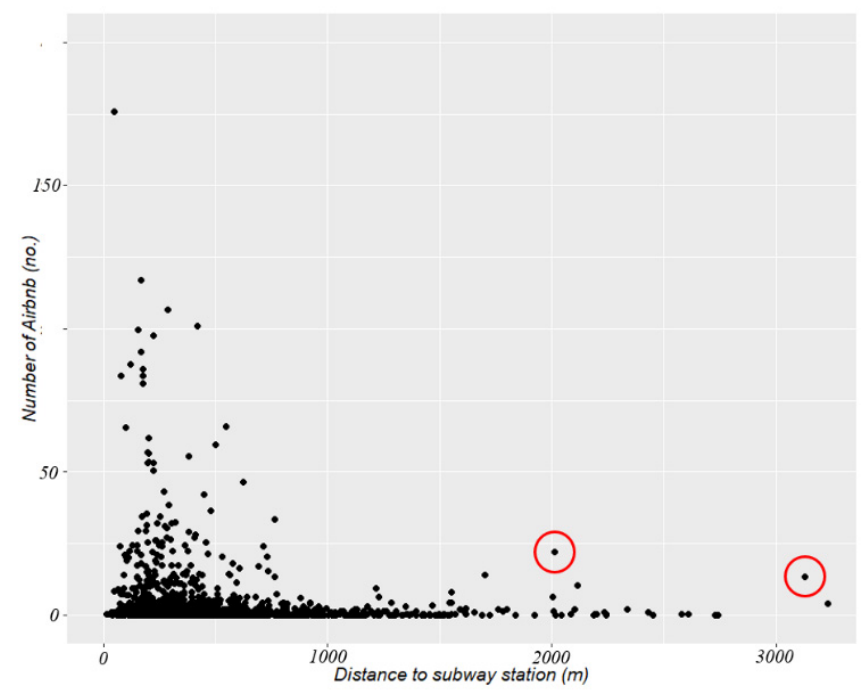

Figure 4. Relationship between distance to subway and no. of Airbnb units.

However, above the threshold ( $849 \mathrm{~m})$, the farther the distance is from the subway, the higher the number of Airbnb units is. Specifically, although statistics showed that the relationship between Airbnb units and distance to the subway station was U-curve, scatter plot (Figure 4) showed this relationship was not a real U-curve. It means that the advantage of accessibility to the subway station disappears beyond the threshold. Some census block groups that are located farther from the subway station but have several Airbnb units (red circles in Figure 4) consist of luxurious single-family houses and quiet residential environments (Buam-dong, Pyeongchang-dong). Thus, distance from a subway station may be offset by the benefits of lodging in luxury housing and a quiet environment. However, 
$96.54 \%$ of Airbnb units are within the threshold distance of a subway station. This means that most Airbnb units are affected by the proximity to subway stations.

The number of other lodging businesses is related to the number of Airbnb units. Other lodgings such as hotels are located in transportation centers or tourist spots [20], which may be similar to the location characteristics of Airbnb units. A number of convenience stores and distance to a university showed statistical significance. Access to convenience stores, which are representative retail shops, is important for Airbnb users. Also, proximity to universities is important due to various amenities, including restaurants and entertainment for young students, that can be appealing to Airbnb guests. On the other hand, the area around the university is densely built with university student housing, and the presence of Airbnb units around the university is likely to reduce the housing available for students.

Finally, this study added an auto-covariate as an independent variable to control spatial autocorrelation, and the Moran's I value was calculated as $0.212(p=0.000)$, with the auto-covariate decreasing by 0.135 from the value without the auto-covariate. This result indicates that, although the auto-covariate did not eliminate spatial autocorrelation, it did reduce the impact significantly.

\subsection{Discussion and Policy Implications}

This study analyzed the locational characteristics of Airbnb units and potential challenges to urban planning and housing policies in Seoul caused by the growth of Airbnb. For this purpose, this study utilized Airbnb location data and examined the determinant factors that affect the locations of Airbnb using negative binomial regression.

The main results and policy implication of this study are as follows. First, descriptive analyses on the operational status of Airbnb in Seoul showed that commercial hosts operated a considerable number of Airbnb units. The percentage of commercially operated Airbnb units in Seoul was greater than those of comparable overseas cities where urban problems associated with Airbnb have been identified. In addition, the spatial analysis of Airbnb indicated that Airbnb is spreading throughout Seoul. Considering several studies pointed out that commercial host is the source of the urban problems such as housing affordability and over-tourism, this study indicated that the substantial growth of Airbnb in Seoul might have similar impacts on surrounding residential areas. Song [17] indicated that the U.S., Germany, France, and the U.K. were enacting regulations on Airbnb through legislation to prevent urban problems. In particular, these governments have regulated the spread of Airbnb by prohibiting the rental of Airbnb units that are occupied by the commercial host. In addition, they limit the number of days of Airbnb rental to a certain period. Therefore, the city of Seoul needs to establish proper regulatory policies to cope with the growth of Airbnb.

Second, negative binomial regression showed that the number of Airbnb units is positively associated with the number of housing units in residential areas. This finding is not surprising, but it is consistent with other previous research [4,11]. Considering that Airbnb units were initially concentrated in the center and then spread to surrounding areas, Airbnb and tourists may penetrate broader residential areas. This circumstance is more likely to aggravate the living environments of surrounding residential areas.

Third, substantial units of Airbnb were located in the residential areas adjacent to universities that have a high proportion of single-person households. In particular, the Korean government has initiated the affordable housing policy for single-person households in residential areas around universities or near the public transport station [35]. Considering the recent surge in the number of single-person households, the growth of Airbnb may cause a challenge to governmental housing affordability policies for in these residential areas. Affordable housing policies for single-person households should be implemented in these areas before the full-fledged conversion of single-person housing units into Airbnb.

Lastly, this study confirmed that the public transportation mobility, proximity to a subway station, and adjacent to convenience stores are important factors to the locations of Airbnb. These amenities 
serve as advantages for foreign tourists who are the primary users of Airbnb. Housing prices, which are the sum of these amenities, had a positive association with the number of Airbnb units, up to a certain level. After a certain level of housing prices, the frequency of Airbnb units decreased, showing a non-linear relationship. This finding indicates that the locational characteristic of Airbnb units has a threshold based on the benefits and costs in the housing market.

Airbnb in Seoul has a potential conflict with governmental housing policies, but there are also benefits associated with Airbnb. For example, it can generate additional revenue for its host and allow users to enjoy "living like a local" at low prices [11]. Therefore, a careful approach will be needed when regulatory policies on Airbnb are implemented. Multi-criteria analysis, which can be used to rationalize choices driven by complex and conflicting various objectives [36], could be useful in this circumstance. Specifically, this method could help in the policy decision-making process for Airbnb, taking into account various criteria related to the effect of Airbnb. Therefore, access from a variety of perspectives is expected in establishing Airbnb regulatory policies or future research.

In addition, considering that Airbnb can cause gentrification and this phenomenon can be concentrated in certain areas [11-13], urban areas that need affordable housing policies could be harmed from the concentration of Airbnb units. In addition, the impact of Airbnb may not be only limited to change in housing price but can lead to changes in various forms of neighborhood environment, such as housing vacancy rate, housing type, and infrastructure. Therefore, future studies need to assess the impacts of Airbnb on the housing market and neighborhood environments through various indicators.

\section{Conclusions}

The recent proliferation of Airbnb has led a discussion of its impact on the housing market, over-tourism, and neighborhood living environments. Several studies reported that Airbnb causes various urban problems, so proper action should be implemented to cope with these issues. In this context, this study examined the potential problems and locational characteristics of Airbnb in Seoul, Korea. This study confirmed that commercial hosts operated a considerable number of Airbnb units in Seoul. This finding indicated that Airbnb might not serve the original intention of the sharing economy. The penetration of Airbnb operated by commercial hosts into residential areas may cause housing problems in terms of housing affordability as well as neighborhood living environments. This study also identified that physical factors such as housing, land use, and public transportation have significant associations with the spatial distribution of Airbnb in Seoul.

This study provides a better understanding of the spatial distributions of Airbnb and their associated factors. Identification of the factors that affect the spatial locations of Airbnb could provide basic knowledge when the government takes proper action to cope with emerging urban problems by Airbnb. "Where are Airbnb units located?" and "Which factors determine Airbnb locations?" might be the most important questions to solve Airbnb related urban problems.

However, this study has a limitation. Although this study analyzed the operation status of Airbnb and locational characteristics of Airbnb to examine potential problems, it was unable to identify the direct impacts of Airbnb on the housing market and neighborhood environments. Also, as with previous studies [5,11-13], the impact of Airbnb can be geographically uneven in Seoul. Therefore, future research needs to address the direct and indirect impacts of Airbnb on the housing market and on neighborhood living environments.

Author Contributions: D.K., the leading author, initially designed the research and performed data analysis. S.L., a corresponding author, developed the original idea of this study and supervised the overall analysis. All authors contributed to manuscript preparation.

Funding: This research received no external funding.

Conflicts of Interest: The authors declare no conflict of interest. 


\section{References}

1. Chung, K.; Cho, K.; Kim, S. The study of availability and factor analysis on car-sharing for sharing economy. Korean Comp. Gov. Rev. 2015, 19, 105-124. [CrossRef]

2. Kang, Y. The sharing economy is good, but Airbnb damage sequence. Midas 2016, 2016, 112-113.

3. Guttentag, D. Airbnb: Disruptive innovation and the rise of an informal tourism accommodation sector. Curr. Issues Tour. 2015, 18, 1192-1217. [CrossRef]

4. Huh, J.; Noh, S. Characteristics and spatial patterns of Airbnb in Seoul. J. Korean Urban Geogr. Soc. 2018, 21, 65-76. [CrossRef]

5. Scott, M. The Impact of Airbnb on NYC Rent; Office of the New York City Comptroller: New York, NY, USA, 2018.

6. Horn, K.; Merante, M. Is home sharing driving up rents? Evidence from Airbnb in Boston. J. Hous. Econ. 2017, 38, 14-24. [CrossRef]

7. Gurran, N.; Phibbs, P. When tourists move in: How should urban planners respond to Airbnb? J. Am. Plan. Assoc. 2017, 83, 80-92. [CrossRef]

8. Lee, D. How Airbnb short-term rentals exacerbate Los Angeles's affordable housing crisis: Analysis and policy recommendations. Harv. Law Policy Rev. 2016, 10, 229.

9. Franco, S.F.; Santos, C.; Longo, R. The Impact of Airbnb on Residential Property Values and Rents: Evidence from Portugal; FEUNL Working Paper Series No. 630; Universidade Nova de Lisboa, Faculdade de Economia: Lisbon, Portugal, 2019. [CrossRef]

10. Sharma, S. Impact of Short Term Rentals on the Rental Affordability in San Francisco-the Case of Airbnb. Master's Thesis, The University of Illinois at Urbana-Champaign, Champaign, IL, USA, 2018.

11. Gutiérrez, J.; García-Palomares, J.C.; Romanillos, G.; Salas-Olmedo, M.H. The eruption of Airbnb in tourist cities: Comparing spatial patterns of hotels and peer-to-peer accommodation in Barcelona. Tour. Manag. 2017, 62, 278-297. [CrossRef]

12. Wachsmuth, D.; Weisler, A. Airbnb and the rent gap: Gentrification through the sharing economy. Environ. Plan A 2018, 50, 1147-1170. [CrossRef]

13. Garcia-Ayllon, S. Urban transformations as an indicator of unsustainability in the P2P mass tourism phenomenon: The Airbnb case in Spain through three case studies. Sustainability 2018, 10, 2933. [CrossRef]

14. Choi, M. A study on failure factors of shared economy accommodation platform Airbnb service brand. $A J$. Brand Des. Assoc. Korea 2017, 15, 231-240. [CrossRef]

15. Lane, J.; Woodworth, R.M. Hosts with Multiple Units-A Key Driver of Airbnb Growth; CBRE: Los Angeles, CA, USA, 2017.

16. Quattrone, G.; Proserpio, D.; Quercia, D.; Capra, L.; Musolesi, M. Who Benefits from the 'Sharing' Economy of Airbnb? In Proceedings of the 25th International Conference on World Wide Web, Montreal, QB, Canada, 11-15 April 2016; pp. 1385-1394. [CrossRef]

17. Song, S. A study on the present state of sharing economy law on Airbnb. J. Consum. Policy Trends 2015, 64, $19-36$.

18. Zhang, Z.; Chen, R.J.C. Assessing Airbnb logistics in cities: Geographic information system and convenience theory. Sustainability 2019, 11, 2462. [CrossRef]

19. Lee, K.; Kim, H.; Kim, H.; Lee, D. The determinants of factors in FIT guests' perception of hotel location. J. Hosp. Tour. Manag. 2010, 17, 167-174. [CrossRef]

20. Yang, Y.; Wong, K.K.; Wang, T. How do hotels choose their location? Evidence from hotels in Beijing. Int. J. Hosp. Manag. 2012, 31, 675-685. [CrossRef]

21. Zervas, G.; Proserpio, D.; Byers, J. The rise of the sharing economy: Estimating the impact of Airbnb on the hotel industry. J. Mark. Res. 2017, 54, 687-705. [CrossRef]

22. Song, Y.; Jung, C.; Yu, S. A hedonic repeated measures approach to the time-serial change in the RevPAR gradients. J. Korea Plan. Assoc. 2008, 43, 79-88.

23. Park, J.; Jeong, G. Seoul International Visitors Survey; Seoul Administration: Seoul, Korea, 2017.

24. Mastercard Destination Cities Index. 2017. Available online: https://newsroom.mastercard.com/wp-content/ uploads/2017/10/Mastercard-Destination-Cities-Index-Deck.pdf (accessed on 5 May 2019).

25. Ryu, S. International Visitors Survey; Korea Tourism Organization: Wonju, Korea, 2017. 
26. Lee, S. A Study on the Development of Location Marking System in the Region; Ministry of the Interior and Safety: Sejong, Korea, 2019.

27. Wang, F.; Xu, Y. Estimating O-D travel time matrix by Google Maps API: Implementation, advantages, and implications. Ann. GIS 2011, 17, 199-209. [CrossRef]

28. Ha, J.; Lee, S. An analysis of vulnerable areas for public transit services using API route guide information. J. Korea Plan. Assoc. 2016, 51, 163-181. [CrossRef]

29. Greene, W. Functional forms for the negative binomial model for count data. Econ. Lett. 2008, 99, 585-590. [CrossRef]

30. Han, J.; Kim, C. Zero inflated poisson model for spatial data. Korean J. Appl. Stat. 2015, 28, 231-239. [CrossRef]

31. Dormann, C.F.; McPherson, J.M.; Araújo, M.B.; Bivand, R.; Bolliger, J.; Carl, G.; Kühn, I. Methods to account for spatial autocorrelation in the analysis of species distributional data: A review. Ecography 2007, 30, 609-628. [CrossRef]

32. Knapp, R.A.; Matthews, K.R.; Preisler, H.K.; Jellison, R. Developing probabilistic models to predict amphibian site occupancy in a patchy landscape. Ecol. Appl. 2003, 13, 1069-1082. [CrossRef]

33. Mitra, R.; Buliung, R.N. The influence of neighborhood environment and household travel interactions on school travel behavior: An exploration using geographically-weighted models. J. Transp. Geogr. 2014, 36, 69-78. [CrossRef]

34. Deng, Y.; Srinivasan, S. Urban land use change and regional access: A case study in Beijing, China. Habitat Int. 2016, 51, 103-113. [CrossRef]

35. Park, M.; Kim, K.; Lee, Y. Housing Policy Responding to One-Person Households Increase; Korea Research Institute for Human Settlements: Sejong, Korea, 2017.

36. Nesticò, A.; Sica, F. The sustainability of urban renewal projects: A model for economic multi-criteria analysi. J. Prop. Invest. Financ. 2017, 35, 397-409. [CrossRef]

(C) 2019 by the authors. Licensee MDPI, Basel, Switzerland. This article is an open access article distributed under the terms and conditions of the Creative Commons Attribution (CC BY) license (http://creativecommons.org/licenses/by/4.0/). 